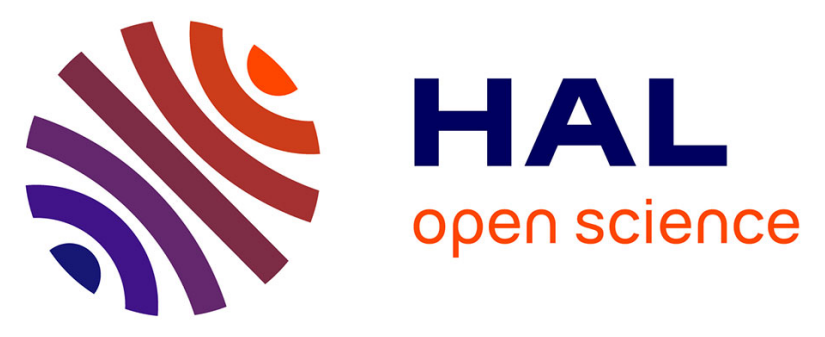

\title{
Randomized phase III trial of adjuvant epirubicin followed by cyclophosphamide, methotrexate, and 5-fluorouracil (CMF) versus CMF followed by epirubicin in patients with node-negative or 1-3 node-positive rapidly proliferating breast cancer
}

Dino Amadori, Rosella Silvestrini, Mario Lena, Francesco Boccardo, Andrea Rocca, Emanuela Scarpi, Francesco Schittulli, Mario Brandi, Roberta Maltoni, Patrizia Serra, et al.

\section{To cite this version:}

Dino Amadori, Rosella Silvestrini, Mario Lena, Francesco Boccardo, Andrea Rocca, et al.. Randomized phase III trial of adjuvant epirubicin followed by cyclophosphamide, methotrexate, and 5fluorouracil (CMF) versus CMF followed by epirubicin in patients with node-negative or 1-3 nodepositive rapidly proliferating breast cancer. Breast Cancer Research and Treatment, 2010, 125 (3), pp.775-784. 10.1007/s10549-010-1257-5 . hal-00598090

\section{HAL Id: hal-00598090 \\ https://hal.science/hal-00598090}

Submitted on 4 Jun 2011

HAL is a multi-disciplinary open access archive for the deposit and dissemination of scientific research documents, whether they are published or not. The documents may come from teaching and research institutions in France or abroad, or from public or private research centers.
L'archive ouverte pluridisciplinaire HAL, est destinée au dépôt et à la diffusion de documents scientifiques de niveau recherche, publiés ou non, émanant des établissements d'enseignement et de recherche français ou étrangers, des laboratoires publics ou privés. 


\section{Randomized phase III trial of adjuvant epirubicin} followed by cyclophosphamide, methotrexate and 5-fluorouracil (CMF) versus CMF followed by epirubicin in patients with node-negative or 1-3 node-positive rapidly proliferating breast cancer

Dino Amadori · Rosella Silvestrini · Mario De Lena - Francesco Boccardo - Andrea Rocca - Emanuela Scarpi · Francesco Schittulli · Anita Mangia - Roberta Maltoni . Patrizia Serra · Riccardo Ponzone · Nicoletta Biglia · Lorenzo Gianni · Amelia Tienghi . Maria Rosaria Valerio · Paola Bonginelli · Laura Amaducci · Marina Faedi · Editta Baldini · Angelo Paradiso

D. Amadori $(\varangle) \cdot$ R. Silvestrini · A. Rocca · E. Scarpi · R. Maltoni · P. Serra Cancer Institute of Romagna (I.R.S.T.), Meldola, Italy Tel: 390543 739912; Fax 390543 739249; e-mail: direzione.scientifica@irst.emr.it

M. De Lena · F. Schittulli · A. Mangia · A. Paradiso ·

National Cancer Institute Giovanni Paolo II, Bari, Italy

F. Boccardo

National Cancer Research Institute and University of Genoa, Genoa, Italy

R. Ponzone · N. Biglia 
Oncological Gynecology Unit, Piedmont Oncology Foundation, Candiolo, and Gynecology and Obstetrics Unit, University of Turin, Mauriziano Umberto I Hospital, Turin

L. Gianni

Department of Medical Oncology, Per gli Infermi Hospital, Rimini, Italy

A. Tienghi

Department of Medical Oncology, S. Maria delle Croci Hospital, Ravenna, Italy

M.R. Valerio

Medical Oncology Unit, University of Palermo, Palermo, Italy

P. Bonginelli

Division of Medical Oncology, Azienda Ospedaliera San Filippo Neri, Rome, Italy

L. Amaducci

Oncology Unit, Degli Infermi Hospital, Faenza, Italy

M. Faedi

Oncology Unit, Maurizio Bufalini Hospital, Cesena, Italy

E. Baldini

Medical Oncology Unit, S. Chiara University Hospital, Pisa, Italy 


\section{Abstract}

Purpose Adjuvant cyclophosphamide, methotrexate, and 5-fluorouracil (CMF) has proven highly effective in rapidly proliferating breast cancer (RPBC). It has also been seen that sequential administration of doxorubicin and CMF is superior to their alternation, especially in indolent tumors. In a phase III study we evaluated whether adjuvant epirubicin $(E)$ followed by $C M F$ is superior to the inverse sequence in RPBC.

Methods Patients with node-negative or 1-3 node-positive RPBC (Thymidine Labeling Index $>3 \%$ or histological grade 3 or S-phase $>10 \%$ or Ki67 $>20 \%$ ) were randomized to receive $\mathrm{E}\left(100 \mathrm{mg} / \mathrm{m}^{2}\right.$ i.v. d1, q21 days for 4 cycles) followed by CMF (600, 40, $600 \mathrm{mg} / \mathrm{m}^{2}$ i.v. d1 \& 8 , q28 days for 4 cycles) $(\mathrm{E} \rightarrow \mathrm{CMF})$ or $\mathrm{CMF}$ followed by $\mathrm{E}(\mathrm{CMF} \rightarrow \mathrm{E})$ or $\mathrm{CMF}$ for 6 cycles.

Results From November 1997 to December 2004, 1066 patients were enrolled: $\mathrm{E} \rightarrow \mathrm{CMF} 440, \mathrm{CMF} \rightarrow \mathrm{E} 438$, and $\mathrm{CMF}$ 188. At a median follow-up of 69 months, 5-year OS was $91 \%(95 \% \mathrm{Cl} 88-94)$ for $\mathrm{E} \rightarrow \mathrm{CMF}$ and $93 \%(95 \% \mathrm{Cl}$ 90-95) for $\mathrm{CMF} \rightarrow \mathrm{E}$, with adjusted hazard ratio of 0.88 (95\% $\mathrm{Cl} 0.58-1.35)$, and DFS was $80 \%$ in both arms, with adjusted hazard ratio of 0.99 (95\% Cl $0.73-$ 1.33, Cox model). Adverse events were similar, apart from a higher rate of neutropenia in the $\mathrm{CMF} \rightarrow \mathrm{E}$ arm.

Conclusions No important differences in clinical outcome were observed between the two different sequences, making both a valid option in early breast 
cancer. Further molecular characterization of the tumors might help to identify subgroups achieving higher benefit from either sequence.

Keywords Sequential adjuvant chemotherapy strategy - Epirubicin . CMF . Randomized phase III study · Rapidly proliferating breast cancer. 


\section{Introduction}

The interplay between tumor cell kinetics and type and sequence of anticancer drugs affects the efficacy of adjuvant chemotherapy. Tumor proliferation is a prognostic marker in breast cancer [1] and affects response to chemotherapy

[2]. Antimetabolites act primarily in specific cell cycle phases and are especially active in rapidly proliferating tumors, as shown by the high efficacy of adjuvant cyclophosphamide, methotrexate, and 5-fluorouracil (CMF) in patients with node-negative, rapidly proliferating breast cancer (RPBC) [3,4]. Anthracyclines have composite mechanisms of action whose contribution to their activity in vivo is still not fully understood [5]: the inhibition of topoisomerase-2 relies mainly on tumor cell proliferation, whereas other mechanisms are less dependent on proliferation.

The superiority of sequential over alternating regimens was predicted by the model of Norton and Simon [6] and confirmed in clinical trials of adjuvant chemotherapy for breast cancer, demonstrating that the sequential administration of four courses of doxorubicin followed by eight courses of CMF yields superior relapse-free and overall survival (OS) rates compared with alternating administration of the same regimens in patients at very high risk of recurrence on the basis of nodal involvement [7]. It is therefore important to establish which regimen should be used first. In a retrospective analysis of the aforementioned trial, the benefit of sequential doxorubicin - CMF was evident mainly in patients with low-intermediate proliferating tumors [8].

We hypothesized that RPBC patients could benefit more from the 
inverse sequence, receiving CMF first in order to kill the subpopulation of highly proliferating cells and then the anthracycline in order to kill the CMF-resistant, probably slowly proliferating subpopulation. To test this hypothesis, we compared the two sequences within a randomized trial. 


\section{Patients and methods}

\section{Study population}

Patients were eligible if they had RPBC, as defined, in order of importance, by thymidine labeling index (TLI) $>3 \%$ or histological grade 3 or S-phase $>10 \%$ or Ki67/MIB1 $>20 \%$. A cutoff of $3 \%$ for TLI has consistently provided prognostic information in large series of patients with early breast cancer $[9,10]$. With regard to S-phase, we previously compared different cell kinetic variables in a series of breast cancer specimens, observing that a median S-phase of $10 \%$ corresponded to a median TLI of about 3\% [11]. Works on Ki67 are based on varying, often arbitrarily chosen cutoffs, and we adopted the threshold of $20 \%$ on the basis of literature data and also because it corresponded to the intermediate value between the overall population median and the median for grade 3 tumors in our series [11]. Further eligibility criteria were: females $\leq 70$ years old; histological diagnosis of invasive breast carcinoma of any size with 13 positive axillary nodes or node-negative tumors $>1 \mathrm{~cm}$; radical tumor resection; no evidence of metastatic disease; white blood cell count $\geq 3500 / \mathrm{mL}$ or neutrophils $\geq 1500 / \mathrm{mL}$, platelets $\geq 120,000 / \mathrm{mL}$, creatinine $\leq$ the upper normal limit (UNL), transaminases and bilirubin $\leq 1.5 \mathrm{UNL}$. Patients gave their written informed consent and women of child-bearing potential were required to have a negative pregnancy test and to use adequate contraceptive measures. Patients were ineligible if they had a previous history of invasive breast cancer or other previous or concomitant malignancies or concomitant diseases which could interfere with study participation. The study was approved by the 
institutional review boards of each participating center and has been registered as a National Cancer Institute trial (NCT01031030).

\section{Study design and treatments}

This was a prospective, randomized, multicenter, open-label phase III trial comparing the efficacy of three treatment arms in patients with RPBC: $E$ for 4 courses followed by CMF for 4 courses $(E \rightarrow C M F)$, CMF for 4 courses followed by $E$ for 4 courses $(\mathrm{CMF} \rightarrow E)$, and $C M F$ alone for 6 courses. The arm with $C M F$ alone was closed after the results of the EBCSG meta-analysis were published in 1998 [12], demonstrating the superiority of anthracycline-based regimens over CMF alone, and the primary objective remained the comparison of $\mathrm{E} \rightarrow \mathrm{CMF}$ with $\mathrm{CMF} \rightarrow \mathrm{E}$. The CMF regimen consisted of cyclophosphamide 600 $\mathrm{mg} / \mathrm{m}^{2}$ iv, methotrexate $40 \mathrm{mg} / \mathrm{m}^{2}$ iv and 5-fluorouracil $600 \mathrm{mg} / \mathrm{m}^{2}$ iv on days 1 and 8, repeated every 4 weeks. Epirubicin was administered every 3 weeks at $100 \mathrm{mg} / \mathrm{m}^{2} \mathrm{iv}$.

Patients with estrogen receptor (ER)-positive tumors received adjuvant tamoxifen for 5 years after the end of chemotherapy. A gonadotropin-releasing hormone $(\mathrm{GnRH})$ agonist could be added in premenopausal patients not achieving amenorrhea after chemotherapy, at the discretion of the participating centers. Patients treated with breast conserving surgery and those submitted to mastectomy for pT3-4 tumors received radiotherapy. Histopathological exams were performed at each participating center and ER and progesterone receptor $(\mathrm{PgR})$ expression was measured by immunohistochemistry in the majority of patients (990 [92.9\%] patients for ER, and 985 [92.4\%] patients for $\mathrm{PgR}$ ), and by the charcoal dextran assay [13] in the remaining cases. HER2/neu positivity 
was determined by immunohistochemistry using Dako Hercep-test or CB11 antibody or by fluorescent in situ hybridization. Tumor proliferation was assessed by TLI in 363 patients (34\%), by histological grade in 601 patients (56\%) and by Ki67/MIB1 in 102 patients (10\%). Grading was considered a surrogate indicator of the proliferative activity based on the strict correlation between the two variables [14].

Baseline workup included medical history, physical examination, laboratory exams, chest x-ray, abdominal ultrasound, bone scan, mammography, ECG and cardiological consultation. Clinical and laboratory assessments were repeated before each cycle and then at 3-month intervals during years 1 and 2 , every 6 months during years 3-5, and yearly thereafter up to the tenth year. Annual chest x-ray, liver ultrasound and bone scans were carried out for the first 5 years and at the discretion of the investigator thereafter. Mammography was performed yearly. Toxicity was recorded at each clinical examination and scored using World Health Organization (WHO) criteria [15]. Dose modifications, based on common criteria, were outlined in the protocol. Colonystimulating factors could be used in the event of grade 4 neutropenia.

\section{Statistical considerations}

The primary endpoint was OS, defined as the time from randomization to the date of last contact or of death for any cause. Secondary objectives were disease-free survival (DFS) and toxicity. DFS was defined as the time from randomization to the date of locoregional or distant recurrence, second invasive breast carcinoma, second primary cancer, and/or death without evidence of breast cancer. Analysis of outcome according to clinical, pathological and 
biological variables was planned in advance, with an explorative intent. The study was performed in accordance with the principles of Good Clinical Practice [16], the ethical standards laid down in the 1964 Declaration of Helsinki [17], and local legal and regulatory requirements.

Within 6 weeks of surgery, patients were randomly assigned to the treatment arms on a 1:1:1 basis by a telephone call to the Biostatistics and Clinical Trials Unit of the coordinating center in Forlì using computer generated randomization lists of permutated blocks of varying sizes stratified for participating center, lymph node status (node-negative versus node-positive) and ER status (ER-negative versus ER-positive). The sequences were concealed from the physicians.

Sample size was determined assuming a 5 -year OS of $75 \%$ for patients treated with 6 cycles of CMF and an expected absolute increase of $8 \%$ in patients treated with $\mathrm{E} \rightarrow \mathrm{CMF}$ or $\mathrm{CMF} \rightarrow \mathrm{E}$ (5\% type I error fixed for a two-sided test and power of $80 \%$ ), planning an accrual of 1200 patients over 3 years. After stopping the CMF arm, the sample size was re-determined assuming a 5-year OS of $78 \%$ for patients treated with $\mathrm{E} \rightarrow \mathrm{CMF}$ and an expected absolute increase of $7 \%$ in patients treated with $\mathrm{CMF} \rightarrow \mathrm{E}$ (5\% type I error fixed for a two-sided test and power of $80 \%$ ). Continuing a 1:1 randomization, a planned accrual period of 36 months, and a follow-up period of 60 months, it was estimated that 400 patients per arm were necessary.

Efficacy analyses were performed according to the intention-to-treat principle. Safety analyses concerned all patients who received at least one dose of study medication. DFS and OS probability and the $95 \%$ confidence interval 
$(95 \% \mathrm{Cl})$ were computed by the Kaplan-Meier product-limit method [18]. The chi-square test or Fisher's exact test were used to compare the incidence and severity of side effects [19]. Estimated hazard ratios (HR) (CMF $\rightarrow$ E versus $\mathrm{E} \rightarrow \mathrm{CMF}, \mathrm{CMF} \rightarrow \mathrm{E}$ and $\mathrm{E} \rightarrow \mathrm{CMF}$ versus $\mathrm{CMF}$ ), their $95 \%$ Cls and $P$ values were calculated from the Cox proportional hazard regression models [20], adjusted according to center, lymph node status and ER status. No interim analysis was planned. No correction for multiple testing was performed in subgroup analyses. The relative dose intensity was calculated as the ratio of the delivered dose intensity, i.e. the ratio of the total dose delivered over total time to complete chemotherapy, to the planned dose intensity. All ' $P$ ' values were based on twosided testing, and statistical analyses were carried out with SAS Statistical Software (version 9.1, SAS Institute). 


\section{Results}

\section{Study details}

Between November 1997 and December 2004, 1066 patients were entered onto the trial by 22 participating centers: 440 were allocated to $\mathrm{E} \rightarrow \mathrm{CMF}, 438$ to $\mathrm{CMF} \rightarrow \mathrm{E}$, and 188 to CMF (Fig. 1). Median follow up was 69 months.

\section{Patient characteristics}

Patients and tumor characteristics were well balanced in the three treatment arms, as reported in Table 1. Median age was 52 years (range 26-70) and 47\% of patients were premenopausal. Most had pT1-2 ductal carcinoma, $47 \%$ with nodal involvement. $79 \%$ had poorly differentiated tumors and median Ki67/MIB1 was 30\%. $62 \%$ had ER-positive ( $\geq 10 \%$ nuclei immunostained or $\geq 10 \mathrm{fmol} / \mathrm{mg}$ protein), 50\% PgR-positive ( $\geq 10 \%$ nuclei immunostained or $\geq 25$ $\mathrm{fmol} / \mathrm{mg}$ protein) and $34 \% \mathrm{ER} / \mathrm{PgR}$-negative disease. HER2/neu was assessed in about half of the patients and was positive in $44 \%$, reflecting the study selection criteria.

Sixty-two percent of the patients had breast conservative surgery and $38 \%$ mastectomy, with axillary dissection in all cases. All patients treated with conservative surgery and $1.4 \%$ of those who underwent mastectomy received radiotherapy, administered in most cases in concomitance with the CMF regimen. All clinical, pathologic and biologic characteristics were well balanced in the three treatment arms. About $83 \%$ of patients with estrogen receptorpositive tumors received adjuvant tamoxifen, which was combined with a $\mathrm{GnRH}$ agonist in a number of premenopausal patients (43\% in the $\mathrm{E} \rightarrow \mathrm{CMF}$ arm, $47 \%$ in the $\mathrm{CMF} \rightarrow \mathrm{E}$ arm, and $27 \%$ in the CMF alone arm). 


\section{Chemotherapy administration and safety}

Seventy-nine percent of patients in the $\mathrm{E} \rightarrow \mathrm{CMF}$ arm, $81 \%$ in the $\mathrm{CMF} \rightarrow \mathrm{E}$ arm, and $84 \%$ in the CMF arm completed the planned chemotherapy. Three percent in each of the two sequential arms and $5 \%$ in the CMF arm stopped treatment in advance due to toxicity, mainly mucositis (11 patients), nausea and vomiting (6), fever-infection (5), and liver toxicity (4). Rarer causes for stopping therapy were neurotoxicity, cardiotoxicity, allergic reactions and myelotoxicity (2 cases each), and actinic dermatitis (1). The remaining patients stopped treatment for other reasons, e.g. treatment refusal, death, progression, lost to follow up. Median relative dose intensity was 0.86 with $\mathrm{E} \rightarrow \mathrm{CMF}, 0.88$ with $\mathrm{CMF} \rightarrow \mathrm{E}$, and 0.88 with CMF.

\section{Toxicity}

Sequential treatments yielded a higher proportion of grade 3-4 side-effects compared with CMF alone, in particular neutropenia $(P=0.03)$ and alopecia $(P<0.0001)$ (Table 2). When the two sequential arms were compared, the only difference was a higher incidence in grade 4 neutropenia in the $\mathrm{CMF} \rightarrow \mathrm{E}$ arm $(12.0 \%$ vs $7.5 \%, P=0.03)$ with respect to the $\mathrm{E} \rightarrow \mathrm{CMF}$ arm. Other grade 4 toxic events included mucositis, increased AST with chronic $\mathrm{C}$ hepatitis, osteoarticular pain, febrile leukopenia, allergic reaction, asthenia with infection, and actinic dermatitis. -One treatment-related death due to myelotoxicity was observed in the arm receiving $\mathrm{E} \rightarrow \mathrm{CMF}$. There were no cases of symptomatic congestive heart failure and the rate of subclinical heart impairment was similar among the three arms; one patient in each sequential arm stopped treatment 
following grade 2 cardiotoxicity. The rate of chemotherapy-induced amenorrhea was $35 \%$ in the $\mathrm{E} \rightarrow \mathrm{CMF}$ arm, $36 \%$ in the $\mathrm{CMF} \rightarrow \mathrm{E}$ arm, and $27 \%$ in the $\mathrm{CMF}$ arm. One patient in the $\mathrm{CMF} \rightarrow \mathrm{E}$ arm was diagnosed with acute myeloid leukemia 27 months after the end of chemotherapy.

\section{Efficacy}

Relevant events are reported in Table 3. Five-year OS was 91\% (95\% Cl 8894) with $\mathrm{E} \rightarrow \mathrm{CMF}$ and $93 \%(95 \% \mathrm{Cl} 90-95)$ with $\mathrm{CMF} \rightarrow \mathrm{E}$, with a hazard ratio adjusted for center, nodes (negative or positive) and ER (negative or positive) status of $0.88(95 \% \mathrm{Cl} 0.58-1.35)$ (Fig. 2a). Five-year DFS was $80 \%$ in both arms $(95 \% \mathrm{Cl} 76-85 \%$ for $\mathrm{E} \rightarrow \mathrm{CMF}$ and $76-84 \%$ for $\mathrm{CMF} \rightarrow \mathrm{E})$, with an adjusted hazard ratio of $0.99(95 \% \mathrm{Cl} 0.73-1.33)$ (Fig. 2b). The analyses conducted on the subgroup of patients for whom TLI was available yielded equivalent results, as did those conducted separately in the subgroup of grade 1-2 tumors and in those of grade 3 tumors (data not shown). Likewise, subgroup analyses according to age ( $<52$ versus $\geq 52$ years), menopausal status, histology, tumor size, nodal status and hormone receptor status did not show any differences between the two sequential arms (Fig. 3).

An exploratory analysis was conducted to compare the group of patients receiving 6 cycles of CMF with those receiving a sequence schedule (either $\mathrm{E} \rightarrow \mathrm{CMF}$ or $\mathrm{CMF} \rightarrow \mathrm{E}$ ) enrolled before the closure of the CMF arm. Five-year OS was $90 \%(95 \% \mathrm{Cl} 87-93)$ with sequential regimens and $90 \%$ with $\mathrm{CMF}(95 \% \mathrm{Cl}$ 86-94), with an adjusted hazard ratio of 0.91 (95\% Cl 0.59-1.42). Five-year DFS was $77 \%$ with sequential regimens (95\% CI $73-82 \%)$ and $78 \%$ with CMF (95\% Cl $72-84 \%)$, with an adjusted hazard ratio of 0.97 (95\% Cl 0.70-1.35). 
Subgroup analyses did not show statistically significant differences in outcome between the two treatments (data not shown). 


\section{Discussion}

Since the publication of the study by Bonadonna and collaborators [21] showing the superiority of four courses of doxorubicin followed by eight courses of $\mathrm{CMF}$ over an alternation of the two regimens, sequential schedules have become a common option for the adjuvant therapy of early breast cancer. Although today the most widely used sequence involves an anthracycline-based scheme followed by a taxane, the problem of the best sequence has yet to be resolved. Our study addressed the issue of which is the best sequence in two non cross-resistant regimens in patients with RPBC, especially important if the two regimens have different efficacy. Delayed administration of the most effective regimen following a less effective treatment is thought to jeopardize its efficacy [22]. Conversely, computer simulations based on mathematical models for tumor growth and treatment suggest the superiority of the "worst drug rule" involving earlier administration of the less effective regimen to rapidly eliminate those cells resistant to the stronger regimen [23].

5-fluorouracil and methotrexate are S-phase specific drugs especially active against highly proliferating cells, while cyclophosphamide is among the alkylating agents with the highest specificity for proliferating cells [24]. Benefit from adjuvant CMF seems, in fact, directly correlated with TLI [3]. Anthracyclines are active during S-phase but also during other phases, including G1, and induce marked cell arrest in G2/M phase [25], suggesting that they may be more active against slowly proliferating tumors when compared with CMF. Response to neoadjuvant doxorubicin plus vincristine appears to be independent of pretreatment TLI [26], and adjuvant treatment of patients with 
node-negative RPBC comprising fluorouracil, epirubicin and cyclophosphamide produces a delayed benefit, typical of therapies that are active in slowergrowing tumors, and independent of proliferative activity [27]. A diverse distribution of tumor cells in the different phases of the cell cycle has been observed after neoadjuvant chemotherapy with different drugs: an accumulation of cells in S-phase after CMF and a higher accumulation in G2/M phase after anthracyclines [28,29].

We hypothesized that the sequence $\mathrm{E} \rightarrow \mathrm{CMF}$ could be highly active in slowly/intermediately proliferating tumors because of the ability of the anthracycline to kill the subpopulation of slowly proliferating cells and to produce a partial synchronization of the remaining, highly proliferating cells sensitive to the S-phase-specific drugs subsequently administered [8]. We also hypothesized that rapidly proliferating tumors could be more effectively treated by administering CMF first in order to kill the subpopulation of highly proliferating cells and then the anthracycline in order to kill the CMF-resistant, probably slowly proliferating subpopulation.

We did not find important differences between the two sequential treatments in terms of either disease-free or overall survival. It must be emphasized that the only variable tested in our study was the different sequence of two regimens as the overall number of cycles administered and the dose intensity of the drugs used were the same in the two arms. A previous study conducted at the Istituto Nazionale Tumori in Milan did not find any difference between CMF given every 3 weeks for 12 courses and 8 courses of the same CMF followed by 4 courses of doxorubicin in patients with early breast 
cancer and one to three involved axillary nodes [30]. Although the differing patient populations, drug regimens (CMF every 21 days in the Milan studies and CMF days 1 and 8 every 28 days in our study) and number of cycles prevent direct comparisons from being made between the two trials, our data suggest that the sequence $\mathrm{CMF} \rightarrow$ anthracycline may be as effective as the more frequently used sequence anthracycline $\rightarrow$ CMF in patients with RPBC, supporting the efficacy of CMF, at least with the schedule used in this study, in these tumors. Further molecular characterization of tumor samples is ongoing to ascertain potential differences between the two sequences based on biomolecular profiles.

There are probably a number of reasons behind the lack of superiority of $\mathrm{CMF} \rightarrow \mathrm{E}$ over $\mathrm{E} \rightarrow \mathrm{CMF}$ in $\mathrm{RPBC}$. Although anthracyclines have multiple mechanisms of action, inhibition of topoisomerase-II- $\alpha$ is one of the most important. Topoisomerase-II- $\alpha$ expression is associated with cell cycle phases, peaking in $\mathrm{G} 2 / \mathrm{M}$ and at its lowest in G0/G1 [31], and is prevalent in highly proliferating cells [32]. Anthracyclines could therefore be as active as antimetabolites in rapidly proliferating cells, in addition to being more active against slowly proliferating ones. On the other hand, cyclophosphamide is also partially active against slowly proliferating cells, contributing to making the two regimens interchangeable. The heterogeneity of proliferation assessment methods in our study may have diluted the differences among treatment arms. Different methodological problems affect the evaluation of tumor proliferation [33]. Although TLI is reliable and reproducible [10,34], its complexity has hampered its widespread diffusion. Ki-67/MIB-1, whilst significantly associated 
with outcome in patients with early breast cancer, has more limited reproducibility [35].

In conclusion, our study does not show important differences between inverse sequences of two non cross-resistant regimens in early RPBC. Taking into account the heterogeneity of breast cancer, the cell cycle specificity of some agents and the cell cycle-related expression of some targets, e.g. topoisomerase-II- $\alpha$, it is possible that further molecular characterization of the tumors could identify subgroups that benefit from a specific strategy. 


\section{Conflicts of interest}

No conflicts of interest to declare. 


\section{Acknowledgements}

The following co-authors are acknowledged: Donata Casadei Giunchi, Cancer Prevention Unit, Morgagni-Pierantoni Hospital, Forlì; Oriana Nanni, Annalisa Volpi, Chiara Tison, Ilaria Massa, I.R.S.T., Meldola; Piero Sismondi, Riccardo Roagna, Oncological Gynecology Unit, Piedmont Oncology Foundation, Candiolo and Gynecology and Obstretrics Unit, University of Turin, Mauriziano Umberto I Hospital, Turin; Alberto Ravaioli, Britt Rudnas, Department of Medical Oncology, Per gli Infermi Hospital, Rimini; Maurizio Marangolo, Federica Zumaglini, Department of Medical Oncology, S. Maria delle Croci Hospital, Ravenna; Nicola Gebbia, Medica Oncology Unit, University of Palermo; Giampiero Gasparini, Division of Medical Oncology, Azienda Ospedaliera San Filippo Neri, Rome; Angelo Gambi, Emanuela Montanari, Oncology Unit, Degli Infermi Hospital, Faenza; Monia Dall'Agata, Oncology Unit, Maurizio Bufalini Hospital, Cesena; Antonio Farris, Giuseppina Sarobba, Department of Medical Oncology, SS Annunziata Hospital, Sassari; Gino Luporini, Riccardo Valsecchi, Department of Medical Oncology, S. Carlo Borromeo Hospital, Milan; Bernardo Leone, Grupo Oncológico Cooperativo del Sur filial Neuquén, Argentina; Giuseppina Catalano, Stefano Luzi Fedeli, Oncology Unit, S. Salvatore Unit, Pesaro; Giorgio Cruciani, Alessandra Piancastelli, Oncology Unit, Lugo Hospital, Lugo; Graziella Furbatto, Department of Obstetrics and Gynecology, S. Andrea Hospital, Vercelli; Mario Nardi, Antonella Falzea, Department of Hematology and Oncology, Bianchi-Melacrino-Morelli Hospital, Reggio Calabria; Biagio Agostara, Adele Traina, Department of Medical Oncology, di Oncologia Medica, M. Ascoli Cancer Hospital, Palermo; Lorenzo Livi, Radiotherapy Unit, erapia, Careggi University Hospital, Florence; Mario Alberto Clerico, Elisa Perfetti, Medical Oncology Unit, Degli Infermi Hospital, Biella; Alessandra Rubagotti, Simona Barozzi, National Cancer Research Institute and University of Genoa, Genoa; Lino Mesi, Senology Unit, M. Ascoli Hospital, Palermo.

The authors wish to thank Gráinne Tierney for editing the manuscript.

This study was funded by CNR-MIUR (as part of the project Progetto Strategico Oncologia) and Istituto Oncologico Romagnolo. 


\section{References}

1. Goldhirsch A, Ingle JN, Gelber RD, Coates AS, Thürlimann B, Senn HJ (2009) Thresholds for therapies: highlights of the St. Gallen International Expert Consensus on the primary therapy of early breast cancer 2009. Ann Oncol 20:1319-1329

2. Amadori D, Volpi A, Maltoni R, Nanni O, Amaducci L, Amadori A, Giunchi DC, Vio A, Saragoni A, Silvestrini R (1997) Cell proliferation as a predictor of response to chemotherapy in metastatic breast cancer: a prospective study. Breast Cancer Res Treat 43:7-14

3. Amadori D, Nanni O, Marangolo M, Pacini P, Ravaioli A, Rossi A, Gambi A, Catalano G, Perroni D, Scarpi E, Giunchi DC, Tienghi A, Becciolini A, Volpi A (2000) Disease-free survival advantage of adjuvant cyclophosphamide, methotrexate, and fluorouracil in patients with nodenegative, rapidly proliferating breast cancer: a randomized multicenter study. J Clin Oncol 18:3125-3134

4. Amadori D, Nanni O, Volpi A, Pacini P, Ravaioli A, Rossi AP, Gambi A, Luzi Fedeli S, Perroni D, Scarpi E, Becciolini A, Silvestrini R (2008) Phase III randomized multicenter study on the effects of adjuvant CMF in patients with node-negative, rapidly proliferating breast cancer: twelve-year results and retrospective subgroup analysis. Breast Cancer Res Treat 108:259264 
5. Minotti G, Menna P, Salvatorelli E, Cairo G, Gianni L (2009) Anthracyclines: molecular advances and pharmacologic developments in antitumor activity and cardiotoxicity. Pharmacol Rev 56:185-229

6. Gilewski T, Norton L (1996) Cytokinetics and breast cancer chemotherapy. In: Harris JR, Lippman ME, Morrow M, Hellman S (eds) Diseases of the Breast. Lippincott-Raven, Philadelphia

7. Bonadonna G, Zambetti M, Valagussa P (1995) Sequential or alternating doxorubicin and CMF regimens in breast cancer with more than three positive nodes. Ten-year results. JAMA 273:542-547

8. Silvestrini R, Luisi A, Zambetti M, Cipriani S, Valagussa P, Bonadonna G, Daidone MG (2000) Cell proliferation and outcome following doxorubicin plus CMF regimens in node-positive breast cancer. Int J Cancer 87:405411

9. Silvestrini R, Daidone MG, Luisi A, Boracchi P, Mezzetti M, Di Fronzo G, Andreola S, Veronesi U (1995) Biologic and clinico-pathologic factors as indicators of specific relapse types in node-negative breast cancer. J Clin Oncol 13:697-704

10. Silvestrini R, Daidone MG, Luisi A, Mastore M, Leutner M, Salvadori B (1997) Cell proliferation in 3,800 node-negative breast cancers: consistency over time of biological and clinical information provided by $3 \mathrm{H}$ thymidine labelling index. Int J Cancer 74:122-127 
11. Barzanti F, Dal Susino M, Volpi A, Amadori D, Riccobon A, Scarpi E, Medri L, Bernardi L, Naldi S, Aldi M, Gaudio M, Zoli W (2000) Comparison between different cell kinetic variables in human breast cancer. Cell Prolif $33: 75-89$

12. Early Breast Cancer Trialists' Collaborative Group (1998) Polychemotherapy for early breast cancer: an overview of the randomised trials. Lancet 352:930-942

13. Piffanelli A, Pellizzola D, Giovannini G, Catozzi L, Faggioli L, Giganti M (1989) Characterization of laboratory working standard for quality control of immunometric and radiometric estrogen receptor assays. Clinical evaluation on breast cancer biopsies. Italian Committee for Hormone Receptor Assays Standardization. Tumori 75:550-556

14. Volpi A, Bacci F, Paradiso A, Saragoni L, Scarpi E, Ricci M, Aldi M, Bianchi S, Muretto P, Nuzzo F, Simone G, Mangia A, Schittulli F, Amadori D (2004) Prognostic relevance of histological grade and its components in node-negative breast cancer patients. Mod Pathol 17:1038-1044

15. World Health Organization: World Health Organization handbook for reporting results of cancer treatment (1979). World Health Organization, Geneva

16. International Conference on Harmonisation of Technical Requirement for Requirements for Registration of Pharmaceuticals for Human Use (ICH Harmonised Tripartite Guidelines): Guideline for good clinical practice 
(GCP) E6 (1996) http://www.ich.org/LOB/media/MEDIA482.pdf.

Accessed 1 February 2009

17. World Medical Association Declaration of Helsinki (1996)

Recommendations guiding physician in biomedical research involving human subjects, adopted by the 18th World Medical Assembly Helsinki, Finland, June amended by 48th General Assembly, Somerset West, South Africa http://www.wma.net/e/polity/pdf/17cpdf. Accessed 1 February 2009

18. Kaplan El, Meier P (1958) Nonparametric estimation for incomplete observation. J Am Stat Assoc 53:457-481

19. Armitage P, Berry G, Matthews JNS (2000) Statistical methods in medical research, 4th edn. Blackwell Publishing, Oxford

20. Cox DR (1972) Regression models and life tables. J R Stat Soc 34:187220

21. Buzzoni R, Bonadonna G, Valagussa P, Zambetti M (1991) Adjuvant chemotherapy with doxorubicin plus cyclophosphamide, methotrexate, and fluorouracil in the treatment of resectable breast cancer with more than three positive axillary nodes. J Clin Oncol 9:2134-2140

22. Martin M (2009) Unravelling the mystery of the TACT trial. Lancet $373: 1662-1663$

23. Day RS (1986) Treatment sequencing, asymmetry, and uncertainty: protocol strategies for combination chemotherapy. Cancer Res 46:38763885 
24. Valeriote F, van Putten L (1975) Proliferation-dependent cytotoxicity of anticancer agents: a review. Cancer Res 35:2619-2630

25. Ling YH, el-Naggar AK, Priebe W, Perez-Soler R (1996) Cell cycledependent cytotoxicity, G2/M phase arrest, and disruption of p34cdc2/cyclin B1 activity induced by doxorubicin in synchronized P388 cells. Mol Pharmacol 49:832-841

26. Silvestrini R, Daidone MG, Valagussa P, Salvadori B, Rovini D, Bonadonna G (1987) Cell kinetics as a prognostic marker in locally advanced breast cancer. Cancer Treat Rep 71:375-379

27. Paradiso A, Schittulli F, Cellamare G, Mangia A, Marzullo F, Lorusso V, De Lena M (2001) Randomized clinical trial of adjuvant fluorouracil, epirubicin, and cyclophosphamide chemotherapy for patients with fastproliferating, node-negative breast cancer. J Clin Oncol 19:3929-3937

28. Daidone MG, Silvestrini R, Luisi A, Mastore M, Benini E, Veneroni S, Brambilla C, Ferrari L, Greco M, Andreola S (1995) Changes in biological markers after primary chemotherapy for breast cancers. Int J Cancer $61: 301-305$

29. Remvikos $Y$, Jouve $M$, Beuzeboc $P$, Viehl $P$, Magdelenat $H$, Pouillart $P$ (1993) Cell cycle modifications of breast cancers during neoadjuvant chemotherapy: a flow cytometry study on fine needle aspirates. Eur J Cancer 29A:1843-1848 
30. Moliterni A, Bonadonna G, Valagussa P, Ferrari L, Zambetti M (1991) Cyclophosphamide, methotrexate, and fluorouracil with and without doxorubicin in the adjuvant treatment of resectable breast cancer with one to three positive axillary nodes. J Clin Oncol 9:1124-1130

31. Woessner RD, Mattern MR, Mirabelli CK, Johnson RK, Drake FH (1991) Proliferation-and cell cycle-dependent differences in expression of the 170 kilodalton and 180 kilodalton forms of topoisomerase II in NIH-3T3 cells. Cell Growth Differ 2:209-214

32. Negri C, Chiesa R, Cerino A, Bestagno M, Sala C, Zini N, Maraldi NM, Astaldi Ricotti GC (1992) Monoclonal antibodies to human DNA topoisomerase I and the two isoforms of DNA topoisomerase II: 170 - and 180-kDa isozymes. Exp Cell Res 200:452-459

33. Colozza M, Azambuja E, Cardoso F, Sotiriou C, Larsimont D, Piccart MJ (2005) Proliferative markers as prognostic and predictive tools in early breast cancer: where are we now? Ann Oncol 6:1723-1739

34. Silvestrini R (1991) Feasibility and reproducibility of the $3 \mathrm{H}$-thymidine labeling index in breast cancer. The SICCAB Group for Quality Control of Cell Kinetic determination. Cell Prolif 24:437-45

35. de Azambuja E, Cardoso F, de Castro G Jr, Colozza M, Mano MS, Durbecq V, Sotiriou C, Larsimont D, Piccart-Gebhart MJ, Paesmans M (2007) Ki-67 as prognostic marker in early breast cancer: a meta-analysis of published studies involving 12,155 patients. Br J Cancer 96:1504-1513 


\section{Figure legends}

Fig. 1 CONSORT diagram.

Fig. 2 Overall (a) and disease-free (b) survival.

Fig. 3 Cox proportional adjusted hazards model of OS and DFS, $\mathrm{E} \rightarrow \mathrm{CMF}$ vs. $\mathrm{CMF} \rightarrow \mathrm{E}$.

Table 1 Characteristics of randomized patients

\begin{tabular}{|c|c|c|c|c|}
\hline & $\begin{array}{c}\text { Total } \\
(n=1066)\end{array}$ & $\begin{array}{l}\text { EPI } \rightarrow \text { CMF } \\
(n=440)\end{array}$ & $\begin{array}{l}\text { CMF } \rightarrow \text { EPI } \\
(n=438)\end{array}$ & $\begin{array}{c}\text { CMF } \\
(n=188)\end{array}$ \\
\hline Characteristic & $\begin{array}{c}\text { No. of patients } \\
\text { (\%) }\end{array}$ & $\begin{array}{c}\text { No. of patients } \\
\text { (\%) }\end{array}$ & $\begin{array}{c}\text { No. of patients } \\
\text { (\%) }\end{array}$ & $\begin{array}{c}\text { No. of } \\
\text { patients (\%) }\end{array}$ \\
\hline Age (years; median [range]) & $52(26-70)$ & $52(26-70)$ & $52(27-70)$ & $50(27-70)$ \\
\hline \multicolumn{5}{|l|}{ Age group, years } \\
\hline$<40$ & $116(10.9)$ & 48 (10.9) & 47 (10.7) & $21(11.2)$ \\
\hline $40-49$ & $338(31.7)$ & $136(30.9)$ & $134(30.6)$ & $68(36.2)$ \\
\hline $50-59$ & $321(30.1)$ & $137(31.1)$ & $134(30.6)$ & $50(26.6)$ \\
\hline$\geq 60$ & $291(27.3)$ & $119(27.1)$ & $123(28.1)$ & $49(26.0)$ \\
\hline
\end{tabular}


Pre-menopause
Post-menopause

Histological type

Ductal

Lobular

Other

pT

T1

T2

T3

T4

Missing

\section{Lymph node status}

Negative
Positive
1
2
3

No. of lymph nodes examined

Median (range)

$\begin{array}{llll}499(46.8) & 201(45.7) & 207(47.3) & 91(48.4) \\ 567(53.2) & 239(54.3) & 231(52.7) & 97(51.6)\end{array}$

$\begin{array}{lccc}954(89.5) & 395(89.8) & 394(90.0) & 165(87.8) \\ 59(5.5) & 21(4.8) & 21(4.8) & 17(9.0) \\ 53(5.0) & 24(5.4) & 23(5.2) & 6(3.2)\end{array}$

$\begin{array}{cccc}498(49.0) & 204(49.0) & 205(48.6) & 89(49.7) \\ 468(46.0) & 196(47.1) & 192(45.5) & 80(44.7) \\ 29(2.8) & 9(2.2) & 16(3.8) & 4(2.2) \\ 22(2.2) & 7(1.7) & 9(2.1) & 6(3.4)\end{array}$

$\begin{array}{lll}49 & 24 & 16\end{array}$

9

$\begin{array}{llll}567(53.2) & 234(53.2) & 231(52.7) & 102(54.3) \\ 499(46.8) & 206(46.8) & 207(47.3) & 86(45.7) \\ 248(23.3) & 101(23.0) & 97(22.1) & 50(26.6) \\ 140(13.1) & 56(12.7) & 65(14.8) & 19(10.1) \\ 111(10.4) & 49(11.1) & 45(10.3) & 17(9.0)\end{array}$




ER-negative
ER-positive
PgR-negative ${ }^{1}$
PgR-positive

\section{Local treatment}

Mastectomy alone

Mastectomy + radiotherapy

Conservative + radiotherapy

$\begin{array}{llll}404(37.9) & 167(37.9) & 164(37.4) & 73(38.8) \\ 662(62.1) & 273(62.1) & 274(62.6) & 115(61.2) \\ 534(50.1) & 210(47.7) & 224(51.1) & 100(53.2) \\ 532(49.9) & 230(52.3) & 214(48.9) & 88(46.8)\end{array}$

$\begin{array}{cccc}394(37.0) & 167(38.0) & 151(34.5) & 76(40.5) \\ 15(1.4) & 4(0.9) & 10(2.3) & 1(0.5) \\ 657(61.6) & 269(61.1) & 277(63.2) & 111(59.0)\end{array}$




\begin{tabular}{|c|c|c|c|c|}
\hline \multicolumn{5}{|l|}{ Systemic treatment } \\
\hline Hormonotherapy (ER+) & $550(51.6)$ & $232(52.7)$ & $220(50.2)$ & $98(52.1)$ \\
\hline Hormonotherapy (ER-) & $60(5.6)$ & $27(6.1)$ & $28(6.4)$ & $5(2.7)$ \\
\hline GnRH agonist & $98(38.8)$ & $45(42.9)$ & $42(46.7)$ & $11(26.8)$ \\
\hline \multicolumn{5}{|l|}{ Grade $^{3}$} \\
\hline 1 & $11(1.1)$ & $7(1.7)$ & $2(0.5)$ & $2(1.2)$ \\
\hline 2 & 200 (19.9) & $79(19.0)$ & $86(20.8)$ & $35(20.1)$ \\
\hline 3 & $793(79.0)$ & $330(79.3)$ & $326(78.7)$ & $137(78.7)$ \\
\hline TLI (\%), median (range) & $5.6(3.1-24.5)$ & $5.2(3.1-24.5)$ & $5.6(3.1-16.7)$ & $5.9(3.1-20.6)$ \\
\hline Missing & 703 & 306 & 286 & 111 \\
\hline Ki67/MIB1 (\%), median (range) & $30(0-98)$ & $30(1-90)$ & $30(0-98)$ & $30(2-90)$ \\
\hline Missing & 152 & 53 & 56 & 43 \\
\hline \multicolumn{5}{|l|}{ HER2 } \\
\hline Positive & $237(43.6)$ & $112(46.3)$ & $97(42.5)$ & $28(37.8)$ \\
\hline Negative & $307(56.4)$ & $130(53.7)$ & $131(57.5)$ & $46(62.2)$ \\
\hline Missing & 522 & 198 & 210 & 114 \\
\hline
\end{tabular}


${ }^{2}$ defined as either $\geq 10 \%$ nuclei immunostained or $\geq 25 \mathrm{fmol} / \mathrm{mg}$ protein

${ }^{3}$ not performed on all cases due to histological type 
Table 2 Toxicity

\begin{tabular}{|c|c|c|c|c|c|c|c|c|c|}
\hline \multirow[b]{3}{*}{ Toxicity } & \multirow{2}{*}{\multicolumn{3}{|c|}{$\begin{array}{c}\mathrm{E} \rightarrow \mathrm{CMF} \\
\text { No. (\%) }\end{array}$}} & \multirow{2}{*}{\multicolumn{3}{|c|}{$\begin{array}{l}\text { CMF } \rightarrow \text { E } \\
\text { No. (\%) }\end{array}$}} & \multirow{2}{*}{\multicolumn{3}{|c|}{$\begin{array}{c}\text { CMF } \\
\text { No. (\%) }\end{array}$}} \\
\hline & & & & & & & & & \\
\hline & Grade 2 & Grade 3 & Grade 4 & Grade 2 & Grade 3 & Grade 4 & Grade 2 & Grade 3 & Grade 4 \\
\hline Leukopenia & $103(24.9)$ & $56(13.6)$ & $7(1.7)$ & $89(21.8)$ & $63(15.4)$ & 15 ( 3.7) & $46(25.0)$ & $20(10.9)$ & $3(1.6)$ \\
\hline Neutropenia & $72(17.4)$ & 82 (19.9) & $31(7.5)$ & 69 (16.9) & $67(16.4)$ & $49(12.0)$ & $31(16.8)$ & $28(15.2)$ & $9(4.9)$ \\
\hline Thrombocytopenia & $10(2.4)$ & $3(0.7)$ & $1(0.2)$ & $9(2.2)$ & $7(1.7)$ & 0 & $4(2.2)$ & $3(1.6)$ & 0 \\
\hline Anemia & $36(8.7)$ & $1(0.2)$ & 0 & $30(7.4)$ & $4(1.0)$ & 0 & $10(5.4)$ & $1(0.5)$ & 0 \\
\hline Alopecia & $58(14.0)$ & $219(53.0)$ & 0 & $58(14.2)$ & $185(45.3)$ & 0 & $25(13.6)$ & $11(6.0)$ & 0 \\
\hline Nausea/vomiting & $148(35.8)$ & 37 ( 9.0) & 0 & $145(35.5)$ & $30(7.4)$ & $3(0.7)$ & $42(22.8)$ & $11(6.0)$ & $1(0.5)$ \\
\hline Diarrhea & $10(2.4)$ & $4(1.0)$ & 0 & $17(4.2)$ & $6(1.5)$ & 0 & $4(2.2)$ & 0 & 0 \\
\hline Mucositis & $48(11.6)$ & $10(2.4)$ & $2(0.5)$ & $29(7.1)$ & $10(2.5)$ & $1(0.2)$ & $12(6.5)$ & $7(3.8)$ & 0 \\
\hline Cardiotoxicity & $2(0.5)$ & 0 & 0 & $4(1.0)$ & 0 & 0 & $1(0.5)$ & 0 & 0 \\
\hline Other & 89 (21.5) & 19 ( 4.6$)$ & $2(0.5)$ & 76 (18.6) & 19 ( 4.7$)$ & $4(1.0)$ & $26(14.1)$ & $8(4.3)$ & 0 \\
\hline
\end{tabular}


Table 3 Events contributing to overall and disease-free survival analysis

\begin{tabular}{|c|c|c|c|c|}
\hline & $\begin{array}{c}\text { Total } \\
(n=1066)\end{array}$ & $\begin{array}{l}E \rightarrow C M F \\
(n=440)\end{array}$ & $\begin{array}{l}\text { CMF } \rightarrow \text { E } \\
(n=438)\end{array}$ & $\begin{array}{c}\text { CMF } \\
(n=188)\end{array}$ \\
\hline Events & $\begin{array}{c}\text { No. of patients } \\
\text { (\%) }\end{array}$ & $\begin{array}{c}\text { No. of patients } \\
\text { (\%) }\end{array}$ & $\begin{array}{c}\text { No. of patients } \\
\text { (\%) }\end{array}$ & $\begin{array}{c}\text { No. of } \\
\text { patients (\% }\end{array}$ \\
\hline All deaths & $115(10.8)$ & $44(10.0)$ & $41(9.4)$ & $30(16.0)$ \\
\hline Cancer & $105(9.8)$ & $40(9.1)$ & $38(8.7)$ & $27(14.4)$ \\
\hline Toxicity & $1(0.1)$ & $1(0.2)$ & 0 & 0 \\
\hline Other & $9(0.8)$ & $3(0.7)$ & $3(0.7)$ & $3(1.6)$ \\
\hline All events contributing to DFS* & $231(21.7)$ & $89(20.2)$ & $89(20.3)$ & $53(28.2)$ \\
\hline Locoregional relapse only & 31 (2.9) & $14(3.2)$ & $12(2.7)$ & $5(2.7)$ \\
\hline Distant relapse only & $141(13.2)$ & $51(11.6)$ & $59(13.5)$ & $31(16.5)$ \\
\hline Bone & $39(3.7)$ & $15(3.4)$ & $15(3.4)$ & $9(4.8)$ \\
\hline Liver & $22(2.1)$ & $8(1.8)$ & $8(1.8)$ & $6(3.2)$ \\
\hline Lung & $10(0.9)$ & $2(0.4)$ & $5(1.1)$ & $3(1.6)$ \\
\hline Supraclavicular lymph nodes & $6(0.6)$ & $3(0.7)$ & $2(0.5)$ & $1(0.5)$ \\
\hline Other & $22(2.1)$ & $8(1.8)$ & $11(2.5)$ & $3(1.6)$ \\
\hline Multiple sites & $42(3.9)$ & $15(3.4)$ & $18(4.1)$ & $9(4.8)$ \\
\hline Second malignancies only: & $49(4.6)$ & $20(4.5)$ & $16(3.7)$ & $13(6.9)$ \\
\hline Contralateral breast cancers & $20(1.9)$ & $12(2.7)$ & $4(0.9)$ & $4(2.1)$ \\
\hline Other sites & $26(2.5)$ & $8(1.8)$ & $10(2.3)$ & $8(4.3)$ \\
\hline Endometrium & $6(0.6)$ & $1(0.2)$ & $2(0.5)$ & $3(1.6)$ \\
\hline Thyroid & $3(0.3)$ & $1(0.2)$ & $2(0.5)$ & - \\
\hline
\end{tabular}


Phase III trial of $\mathrm{E} \rightarrow \mathrm{CMF}$ vs $\mathrm{CMF} \rightarrow \mathrm{E}$ in $\mathrm{N}-, 1-3 \mathrm{~N}+$ highly proliferating $\mathrm{BC}$

36

$\begin{array}{lllll}\text { Lung } & 3(0.3) & 1(0.2) & 1(0.2) & 1(0.5) \\ \text { Colon } & 3(0.3) & 1(0.2) & 1(0.2) & 1(0.5) \\ \text { Uterus } & 2(0.2) & 1(0.2) & - & 1(0.5) \\ \text { Other } & 12(1.1) & 3(0.7) & 6(1.4) & 3(1.6) \\ \text { Deaths without breast cancer } & 10(0.9) & 4(0.9) & 2(0.5) & 4(2.1)\end{array}$

*DFS (disease-free survival) events: locoregional + distant metastases + second malignancies + deaths without breast cancer 